\title{
Analysis of EGR Coupled Less Heat Rejection Model of Diesel Engine with Blends of Jatropha Biodiesel, Diesel and Diethyl Ether: An Experimental Approach
}

\author{
K. V. Krishna ${ }^{1 *}$, G. R. K. Sastry ${ }^{1}$ and M. V. S. M. Krishna ${ }^{2}$ \\ ${ }^{1}$ Department of Mechanical Engineering, National Institute of Technology Agartala, \\ Tripura State, India \\ *Email: masikrish@gmail.com \\ ${ }^{2}$ Department of Mechanical Engineering, CBIT, \\ Hyderabad, Telangana State, India
}

\begin{abstract}
The experimental investigation on a less heat rejection model (LHRM) of the diesel engine was done with the objective to improve the performance and emission characteristics. The LHRM has a bond coat of NiCrAl interposed between the thermal barrier ceramic coated cylinder head and liner of the engine. The model is coupled with exhaust gas recirculation (EGR) system at a constant rate of $10 \mathrm{vol} . \%$. The test fuels are neat diesel for the non-coated engine (NCE) and blends with different ratios of dieselJatropha biodiesel, keeping a constant ratio of additive diethyl ether (DEE) for the LHRM. The load was varied from 0 to $100 \%$ and injection timing (IT) from $29^{\circ}$ to $34^{\circ}$ BTDC. The performance parameters of both engines improved significantly with the advancement of the injection timing. The NOx emissions reduced with no effect on BSEC, BTE and smoke levels with $10 \%$ EGR rate. The optimum blend and IT for LHRM are D20JB60A20 by vol. (20\% of diesel $+60 \%$ of Jatropha biodiesel $+20 \%$ of additive DEE) and $32^{\circ}$ BTDC as the maximum enhancement of about 6 to $7 \%$ in peak BTE with a reduction in BSEC by $9.5 \%$, EGT by $18 \%$, VE by 2 to $3 \%$, smoke level by $44.5 \%$ and NOx emissions by $14.2 \%$ were found compared to NCE with diesel at normal operating conditions. At advanced injection timings with a higher load, in comparison to NCE, LHRM showed significant improvement in all of the investigated parameters.
\end{abstract}

Keywords: Less heat rejection model; yttria-stabilized zirconia; exhaust gas recirculation; injection timing; diethyl ether additive; Jatropha biodiesel.

\section{NOMENCLATURE}

$\begin{array}{ll}\text { LHRM } & \text { less heat rejection model } \\ \text { NCE } & \text { non-coated engine } \\ \text { JB } & \text { jatropha biodiesel } \\ \text { DEE } & \text { diethyl ether } \\ \text { YSZ } & \text { yttria stabilized zirconia } \\ \text { NiCrAl } & \text { nickel-chromium-aluminum } \\ \text { EGR } & \text { exhaust gas recirculation } \\ \text { BTDC } & \text { before top dead center } \\ \text { BTE } & \text { brake thermal efficiency } \\ \text { EGT } & \text { exhaust gas temperature } \\ \text { BSEC } & \text { brake specific energy consumption } \\ \text { VE } & \text { volumetric efficiency }\end{array}$


$\mathrm{NO}_{\mathrm{x}} \quad$ nitrous oxide

IT injection timing

\section{INTRODUCTION}

The prime objectives of developing any new energy source or to enhance the efficacy of a conventional energy source should be eco-friendly, renewable and reliable. Regarding I.C. Engines, for the moment, the energy originated from fossil fuel source was known to be optimum because of reasons like matured technology and reliability. But the unacceptable level of pollutants in atmosphere emitted from the burning of fossil fuel and the prompt depletion of reserves develop a quest in every scientific temper person to find alternatives. The prime responsibility to fulfill the objectives lies with the internal combustion engine researchers. The carbon dioxide ratio in the atmospheric was at a continuously increasing rate due to the burning of fossil fuels at a rapid rate. Consequently, the earth crosses the climate danger threshold by 2036 that severely damages the human civilization and the ecological imbalance [1]. The $48 \%$ rise in global world energy consumption signifies the acute need for alternative energy sources to satisfy the rapidly rising demand [2]. From the recent past, the research in energy shows a shift towards novel energy sources and their real-time production. Biodiesel can also serve as the fossil fuel in its absence for compression ignition engines as revealed by reports $[3,4]$. The reasons for this is due to exhibition of fuel properties within the standards laid by agencies, environmentally friendly nature, and improved engine performance. The wide variation in the biodiesel fuel properties is related to the type of source feedstock. The capability of non-edible biodiesel oil sources like Jatropha, Karanja, Rubber seed, Linseed and tobacco as an alternative fuel to diesel was evident from a remarkable reduction in $\mathrm{CO}, \mathrm{HC}$ and particulate emissions with a little improvement in BTE. However, NOx was increased [5].

The review study done by Pandey, et al. [6] have found multiple benefits of jatropha besides a reliable biodiesel source. It provides a comprehensive understanding of different ecological, environmental and economic aspects of Jatropha. The studies [7, 8] on jatropha biodiesel with its blends in the ordinary diesel engine showed an increase in specific fuel consumption with a reduction in unburnt $\mathrm{HC}$, carbon monoxide and carbon dioxide emissions except for NOx. The addition of oxygenated additives (nbutanol and diethyl ether) with blends of diesel and Jatropha biodiesel showed improvement in emission, combustion, and performance of the turbocharged indirect injection multi-cylinder diesel engine. The fuel characteristics enhanced due to the addition of additives [9]. A similar conclusion was reported in the study done by Imtenan et al. [10]. The analysis of regulated and unregulated exhaust emission of a diesel engine fuelled by jatropha biodiesel and its blends have found that increase of biodiesel ratio in the fuel blend increases the formaldehyde and NOx emissions. However, the emissions like CO, HC, smoke, and toluene decreases [11]. The study done by Shameer, et al. [12] on injection parameters (injection timing and injection pressure) of a diesel engine fuelled by different biodiesels has found that advancement in injection timing improved performance and emission characteristics. However, NOx emissions increased for the same. A similar conclusion is reported in the study done by Rostami et al. [13]. Blending the biodiesel with any viscosity reduction additive such as diethyl ether reduces its viscosity. Using this blend and an early fuel injection improves the performance and combustion characteristics. Blending reduces all the emissions [14]. The semi adiabatic diesel engine fuelled by the blend of biodiesel and additive diethyl shown higher 
performance and combustion with improved emission characteristics compared to a diesel engine with diesel. The $10 \%$ exhaust gas recirculation (EGR) rate found to be optimum for a low heat rejection engine [15]. A similar conclusion is reported in the study done by Kulkarni, et al. [16].

The performance and combustion characteristics of a non-coated diesel engine were lower compared to the PSZ coated one fuelled by palm biodiesel with cetane improver additive [17]. The diesel engine combustion and emissions characteristics improved for the blends having a low ratio of Jatropha biodiesel. A linear increase in brake power and torque with the increase in engine speed [18]. The emission, combustion and performance characteristics of a diesel engine are enhanced by an early injection of the jatropha biodiesel. On the other hand, retardation gives the results opposite to the former but decreases the emission of NOx [19]. For a dual-fuel diesel engine, better performance and emission characteristics with fuel combinations of producer gas and diesel as base fuels and neat and preheated jatropha methyl ester as injected fuels can be achieved by a slight modification to the diesel engine [20]. Thus from the literature knowledge, a minor modification to the combustion chamber was made to curb the heat loss to coolant and core engine components named it as LHRM. The LHRM was developed with suitable thermal barrier materials and fuelled by the blends of jatropha biodiesel-additive diethyl ether-diesel. An experiment attempted with the LHRM with varied operating conditions seeking improvement in performance and emission characteristics.

\section{MATERIALS AND METHOD}

\section{Test Fuels}

Purchasing the fuels diesel, Jatropha biodiesel and the additive diethyl ether was done at the certified local supplies. Assessment of the properties along with the preparation of the fuel blends was carried out in the laboratory. The different fuel blends investigated with LHRM were:

a) $0 \%$ diesel $+80 \%$ Jatropha biodiesel $+20 \%$ Additive DEE (D0JB80A20)

b) $20 \%$ diesel $+60 \%$ Jatropha biodiesel $+20 \%$ Additive DEE (D20JB60A20)

c) $40 \%$ diesel $+40 \%$ Jatropha biodiesel $+20 \%$ Additive DEE (D40JB40A20)

d) $60 \%$ diesel $+20 \%$ Jatropha biodiesel $+20 \%$ Additive DEE (D60JB20A20)

e) $80 \%$ diesel + 0\% Jatropha biodiesel + 20\% Additive DEE (D80JB0A20).

The optimum blend found was D20JB60A20. In this paper, the performance and emission characteristics of LHRM with the optimum blend and NCE with neat diesel were discussed. Table1 gives the important properties of fuels.

Table 1. Significant properties of test fuels.

\begin{tabular}{lcccc}
\hline \multicolumn{1}{c}{ Fuel } & $\begin{array}{c}\text { Density at } \\
40^{\circ} \mathrm{C} \\
\left(\mathrm{kg} / \mathrm{m}^{3}\right)\end{array}$ & $\begin{array}{c}\text { Viscosity at } \\
40^{0} \mathrm{C} \\
\left(\mathrm{mm}^{2} / \mathrm{sec}\right)\end{array}$ & $\begin{array}{c}\text { Flashpoint } \\
\left({ }^{0} \mathrm{C}\right)\end{array}$ & $\begin{array}{c}\text { Calorific } \\
\text { value } \\
(\mathrm{MJ} / \mathrm{kg})\end{array}$ \\
\hline Diesel & 840.0 & 2.60 & 74.0 & 42.5 \\
Jatropha biodiesel & 895.0 & 3.80 & 115.0 & 39.4 \\
Diethyl ether & 712.0 & 0.24 & -45.0 & 35.0 \\
D20JB60A20 blend & 847.4 & 2.87 & 74.8 & 39.1 \\
\hline
\end{tabular}




\section{Development of Less Heat Rejection Model (LHRM)}

In high-temperature applications, the 8 YSZ ceramic (zirconium oxide ceramic stabilized with $8 \%$ yttrium oxide), a popular thermal barrier coating material having characteristics such as very low thermal conductivity and high thermal shock resistance is deployed. In the current study, the YSZ ceramic powder was used for coating the cylinder head and liner of the diesel engine. Adhesion is provided by the bond coat which is interfaced between the ceramic top coat and the substrate. This bond coat also gets oxidized to form a slow-growing protective oxide layer [22]. Applying a bond coat improves the life of the component. NiCrAl (Ni $22 \%, \mathrm{Cr} 11 \%$, and $\mathrm{Al} 67 \%$ ) was used to serve this purpose.

The coating process was started with the application of bond coat $\mathrm{NiCrAl}$ of 100micron thickness on the inner portion of the cylinder head over which the 8 YSZ ceramic powder of 300-micron thickness was coated uniformly by a Plasma spray gun. The alphabets $\mathrm{A}$ and $\mathrm{B}$ in Figure 1 drawn using $\mathrm{CAD}$ (computer aided drawing) represent the 8 YSZ ceramic coating and the inner portion of cylinder head respectively. YSZ and the bond coat $\mathrm{NiCrAl}$ were deployed to coat the outer portion of the cylinder liner in the same way. The alphabets $\mathrm{C}$ and D in Figure 2 drawn using CAD represent the 8 YSZ ceramic coatings and the outer portion of cylinder liner respectively. Table 2 provides the required information about the significant properties of the 8 YSZ ceramics where Table 3 gives the details about the plasma spray coating process.

Table 2. Significant properties of 8 YSZ ceramic [21].

\begin{tabular}{lc}
\hline Parameter & Specification \\
\hline Melting point & $>2600{ }^{0} \mathrm{C}$ \\
Modulus of elasticity & $40 \mathrm{GPa}$ \\
Thermal expansion & $10.9^{*} 10^{-6} \mathrm{~K}^{-1}$ \\
Thermal conductivity & $2.5-3 \mathrm{~W} / \mathrm{m}-\mathrm{K}$ \\
\hline
\end{tabular}

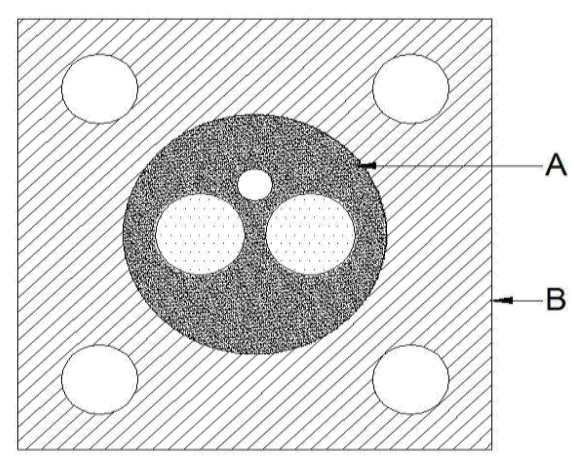

Figure 1. Cylinder head with 8 YSZ ceramic coating (A) and inner portion (B). 


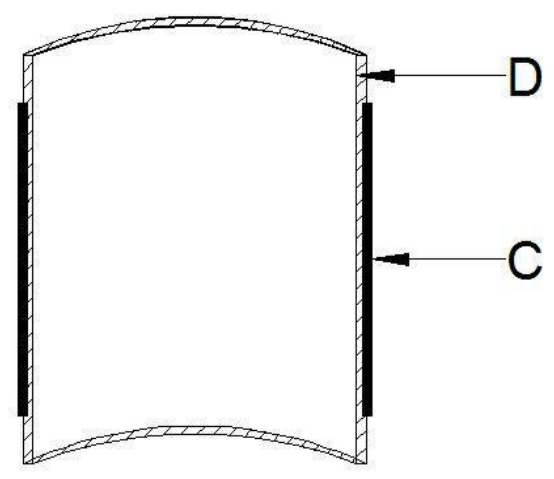

Figure 2. Cylinder liner with 8 YSZ ceramic coating (C) and outer portion (D).

Table 3. Details of plasma spray coating.

\begin{tabular}{ll}
\hline Parameter & Specification \\
\hline Plasma gun model & $3 \mathrm{MB}$ \\
Power applied (kW) & 22 \\
Distance of spray (inches) & $2-3$ \\
Gas pressure (Hydrogen in psi) & 35 \\
Gas pressure (Argon in psi) & 85 \\
Feed rate of powder (grams per minute) & $36-40$ \\
\hline
\end{tabular}

Table 4. Specifications of test engine.

\begin{tabular}{ll}
\hline Parameter & Specification \\
\hline Engine make & Kirloskar, India \\
Number of cylinders & one \\
Bore X Stroke & $90 \mathrm{~mm}$ X 120mm \\
Compression ratio & $18: 1$ \\
Method of engine cooling & Water cooled \\
Rated speed (Constant) & $1500 \mathrm{rpm}$ \\
Fuel injection system & In line and direct injection \\
Supplier recommended injection timing and pressure & $29^{0}$ BTDC X 190 bar \\
Number of holes of injector and size & 3 X 0.25 mm \\
Type of loading & Electrical dynamometer \\
\hline
\end{tabular}

\section{Experimental Setup}

The engine test rig was shown in Figure 3. Table 4 gives the specifications of the engine. The load was applied by an Eddy current type dynamometer. The consumption of fuel was measured by an arrangement of three-way valve and a calibrated burette. The continuous damp free air was supplied to the engine inlet manifold by an air box arrangement. The differential pressure across the orifice was measured using a $U$ tube water manometer while a resistance type thermometer was used to measure the inlet and outlet temperature of the water which is used as the coolant. The K-type thermocouple comes into the picture for measuring the exhaust gas temperature. Throughout the study, a fuel injection pressure of 190 bar, a compression ratio of 18:1 and engine speed of 1500 
rpm were kept constant. An arrangement of exhaust gas recirculation system with a control valve was provided at the inlet to enable the flue gases to flow and meet the fresh air with a constant rate of $10 \%$ by vol.

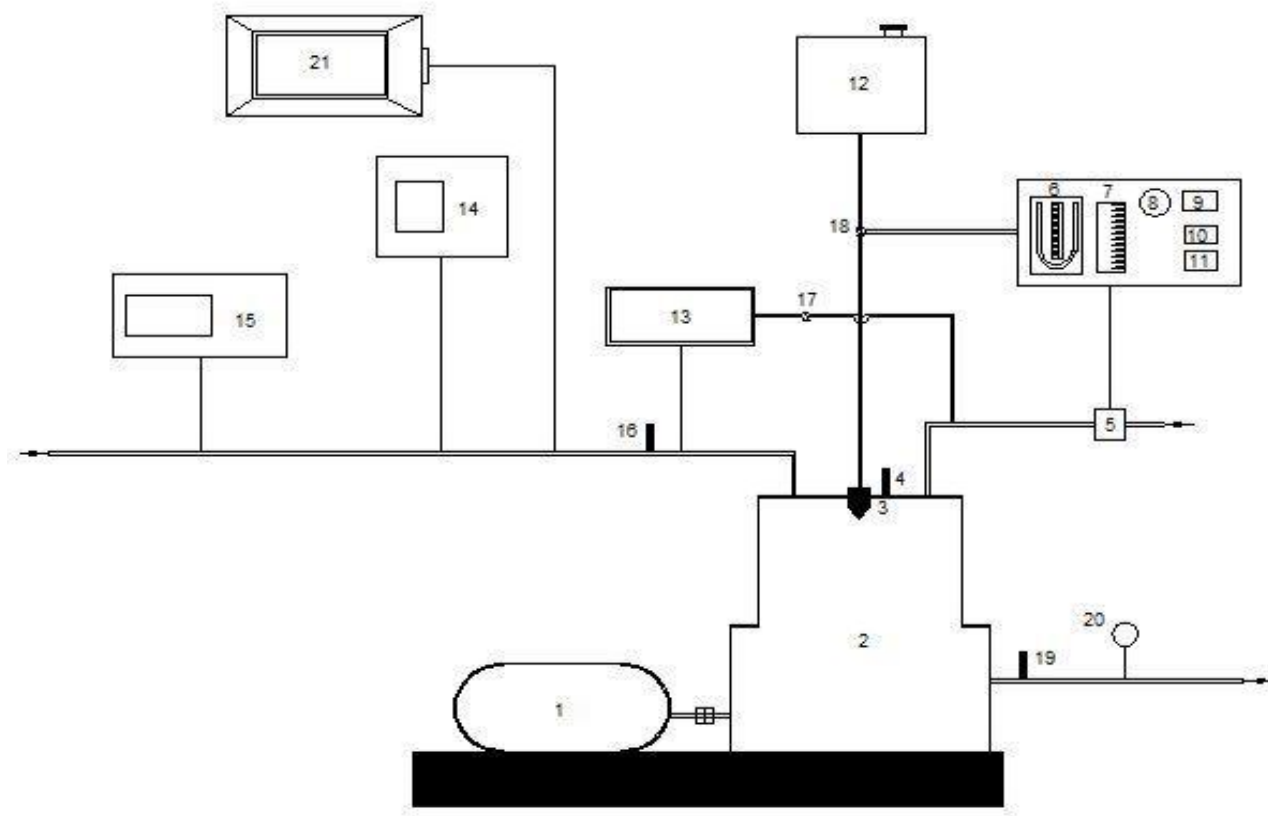

1. Eddy current dynamometer 2. Test Engine 3. Fuel injector 4. Pressure sensor 5. Airbox 6. Utube water manometer 7. Burette 8. Load switch 9, 10 \& 11 Ammeter, Voltmeter \& Speed indicator 12. Fuel tank 13. Exhaust gas recirculation (EGR) system 14. NOx analyzer 15. Smoke analyzer 16. Exhaust gas Temperature indicator 17. Control value 18. Three-way value 19. Water outlet temperature indicator 20. Water flow meter 21. Data acquisition system/computer

Figure 3. Schematic of experimental engine test rig setup.

\section{Experimental Procedure}

The experimentation started after the non-coated diesel engine attained a steady state. The performance and emission characteristics of NCE fuelled by neat diesel were measured with a varied load for different injection timing. The chief objective of developing LHRM was to curb the heat energy lost to the coolant and engine components. Different fuel blends were used for carrying out the similar procedure with LHRM. The injection timing (IT) was varied from $28^{\circ}$ BTDC to $34^{\circ}$ BTDC using copper shims of suitable size placed between engine frame and pump body seeking an optimum performance. Evaluation of the performance and the emission characteristics like the brake thermal efficiency(BTE), brake specific energy consumption (BSEC), volumetric efficiency(VE), exhaust gas temperature(EGT), smoke levels and NOx emissions were done for both the versions of the diesel engine. 


\section{RESULTS AND DISCUSSION}

\section{Performance Characteristics}

The variation in brake thermal efficiency (BTE) of non-coated engine with neat diesel at varied loads $(0,20,40,60,80$ and $100 \%)$ for different injection timings (IT) was shown in Figure 4. It was found that the advancement in injection timing significantly enhances the BTE. The maximum BTE of $32.5 \%$ was obtained at an advanced IT $34^{\circ}$ BTDC with $90 \%$ of full load and a minimum of $29.5 \%$ was found at an IT $29^{\circ}$ BTDC with $90 \%$ of full load. The decrease in BTE beyond $90 \%$ load might be due to the drop in fuel conversion and mechanical efficiencies. Hence, the optimum configuration found for NCE was $34^{\circ}$ BTDC with $90 \%$ of full load.

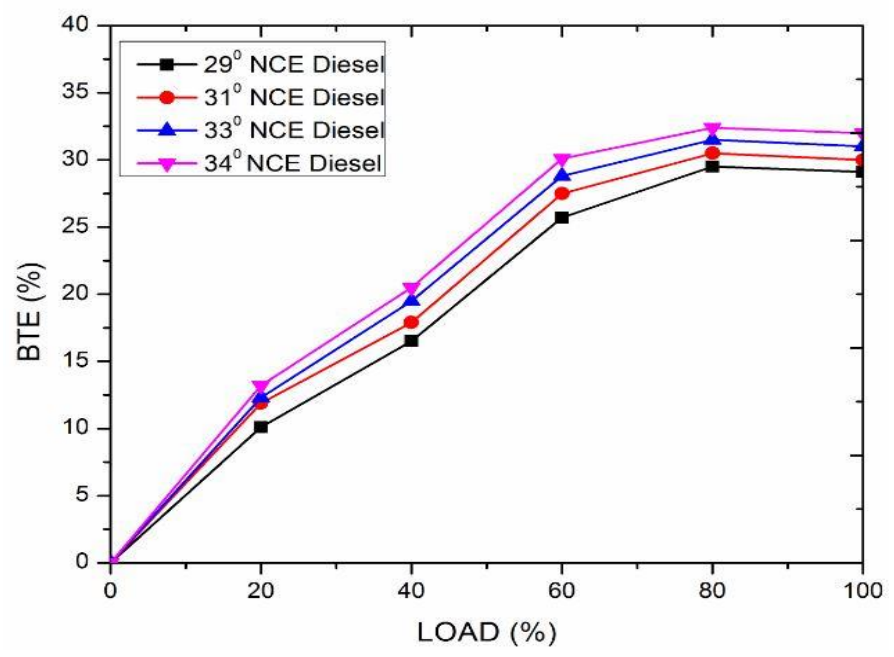

Figure 4. BTE vs load for different injection timing of NCE with diesel.

For all the test fuels, injection timing (IT) advancement has shown an increase in the brake thermal efficiency (BTE) for both versions (NCE \& LHRM) of the diesel engine. This was due to the early charge combustion in the working cycle that resulted in the burning of the maximum fraction of charge before TDC. Consequently, the incylinder peak pressure moves closer to TDC thus enhancing the BTE [15].

Figure 5 shows the variation in BTE of LHRM fuelled by the optimum blend D20JB60A20 at varied loads for different injection timings (IT). The maximum enhancement of BTE of about 6 to $7 \%(36.5 \%)$ was found with the optimum blend D20JB60A20 at an IT $32^{\circ}$ BTDC with $90 \%$ of full load compared with NCE fuelled by neat diesel at normal operating conditions.

Also, the blend D0JB80A20 gives closer results to the optimum blend. This might be due to the higher amount of oxygen content with the high ratio biodiesel blends and gain in the heat energy of LHRM that ensured better blend vaporization and complete combustion. Hence, the LHRM was more suitable for the blends having a higher ratio of biodiesel. 


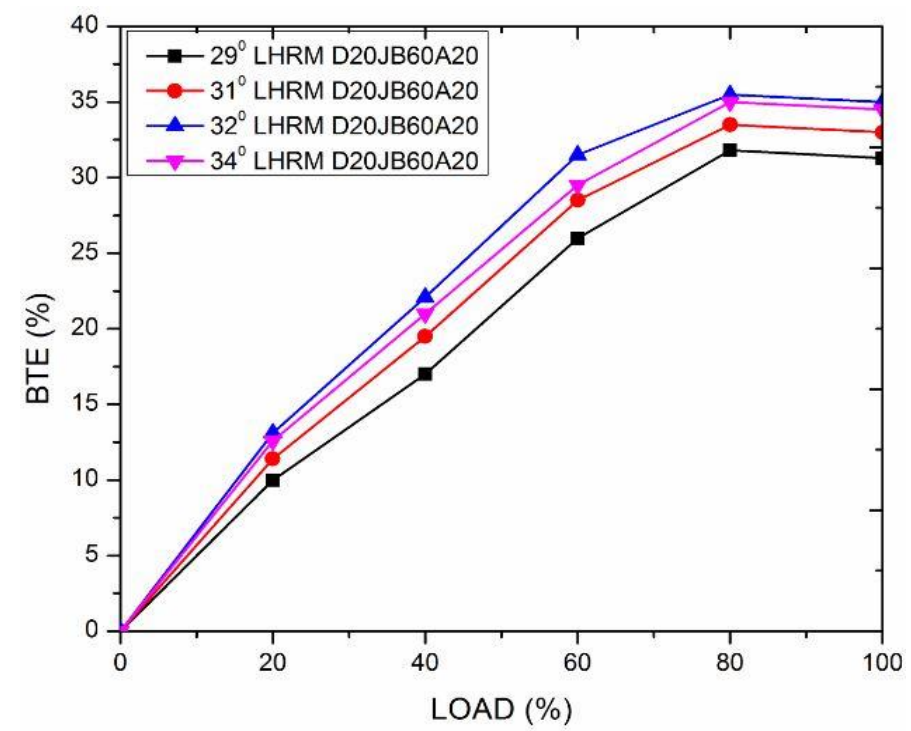

Figure 5. BTE vs load for different injection timing of LHRM with blend D20JB60A20.

At lower loads, the variation in parameters of BSEC, EGT, VE, and emissions like Smoke and NOx are less. Hence, the results of these parameters were presented and discussed at the full load for different injection timing (IT) using bar charts. Figure 6 shows the variation of BSEC of NCE and LHRM fuelled with diesel and optimum blend D20JB60A20 respectively at full load for different injection timing. It was found that with advancement in injection timing, the BSEC gets improved significantly and the BSEC of LHRM was lower compared to NCE at any specific injection timing.

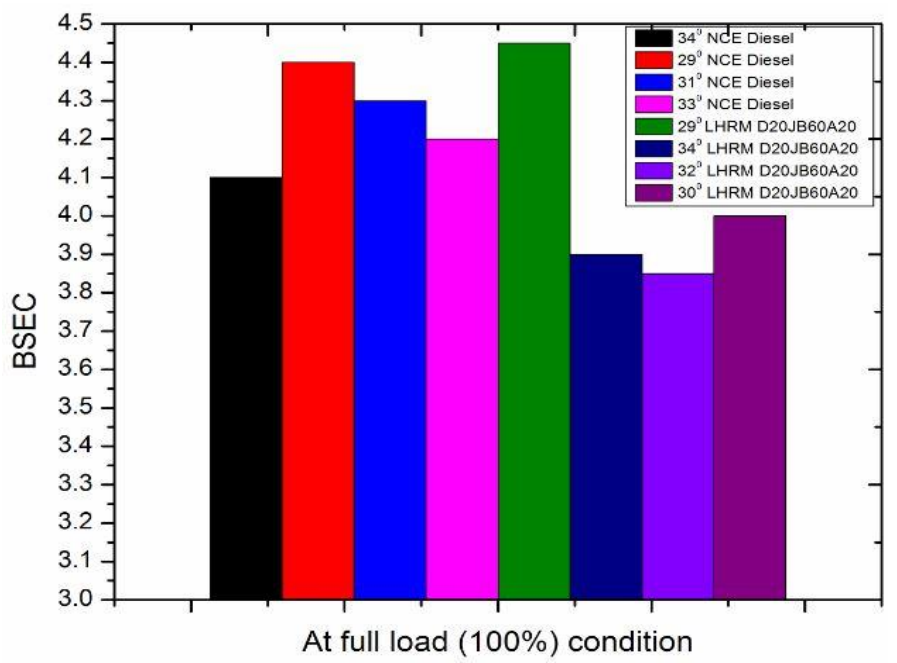

Figure 6. BSCE of LHRM and NCE for different injection timing at full load.

The optimum BSEC of LHRM was found to be $9.5 \%$ at an injection timing of $32^{\circ} \mathrm{BTDC}$ and it was $5 \%$ with NCE at $34^{\circ}$ BTDC. This took place because of the lower volatility of the blend and higher biodiesel ratios (60 and $80 \%)$. The addition of diesel and additive DEE $20 \%$ by vol. with biodiesel reduced the viscosity of the blend. Consequently, giving a higher BTE with a lower BSEC for LHRM. Advancing the 
injection timing contributes to early combustion phase in the cycle ensuring complete burning of fuel. This results in an increase of BTE with a decrease of BSEC. The availability of oxygen content in the blend D20JB60A20 is 12 to 13\%. This, when used in the LHRM at a higher or a full load makes the blend get burnt completely. The $10 \%$ rate of EGR was known to be optimum [15] and it is proved again as it has hardly shown any effect on BSEC.

Figure 7 shows the EGT results of both LHRM and NCE fuelled by D20JB60A20 and diesel respectively for different injection timings at full load. At any specific injection timing, the EGT follows a linearly increasing trend while an advancement in the injection timing gives a linearly decreasing trend at full load for both the engines. For all the blends with LHRM, EGT was lower compared to NCE fuelled by diesel irrespective of injection timings. The reduction in EGT of LHRM was found to be $18.5 \%$ with blend D20JB60A20 at $32^{\circ}$ BTDC and $16.5 \%$ at $34^{\circ}$ BTDC compared to NCE fuelled by diesel at $29^{\circ} \mathrm{BTDC}$ respectively. Inspection of the experimental results revealed that the highest EGT value was found for lower BTE and the lowest EGT for a higher BTE condition. The reasons for the EGT decrease with LHRM might be due to the combined effect of ample hot combustible environment in the combustion chamber, high compression ratio 18:1 operation and advancement in Injection timings that ensured complete burning of fuel blend that leads to enhancement in BTE and consequently resulting in a decreasing trend of EGT. The EGT found to be increased by about 2 to $4 \%$ at each load step and biodiesel ratio in fuel blend by $20 \%$ irrespective of IT.

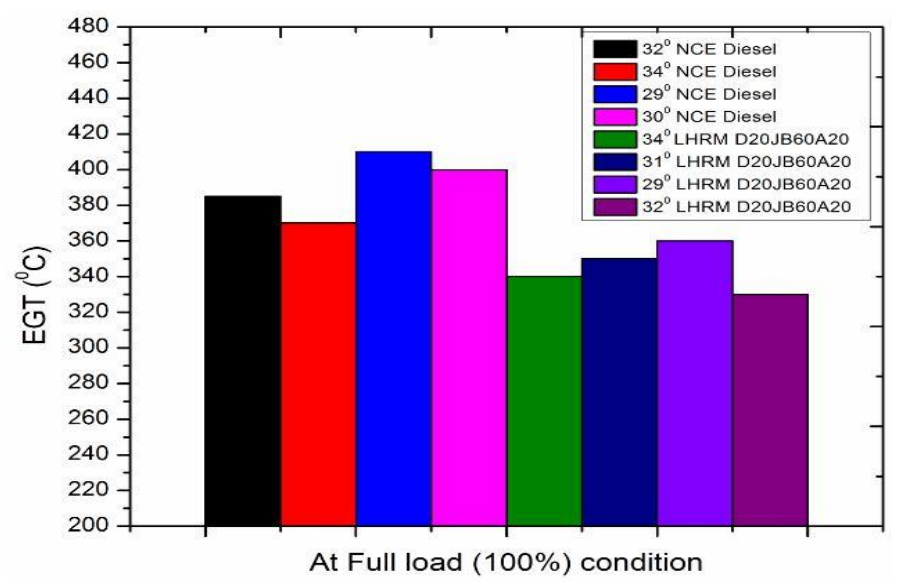

Figure 7. EGT of LHRM and NCE for different injection timing at full load

Figure 8 shows the volumetric efficiency results of NCE and LHRM fuelled by diesel and blend D20JB60A20 respectively operated at full load at different injection timings. It was found that the volumetric efficiencies of LHRM with different blends were lower by 3 to $6 \%$ compared to NCE with diesel. The minimum reduction in VE of LHRM was $3 \%$ found for the blend D20JB60A20 at 32 ${ }^{\circ}$ BTDC. The decrease in VE of LHRM with blends might be due to the reduction in inlet air density due to the existence of very high combustion temperature and the provision of $10 \%$ EGR to inlet manifold of the engine. The volumetric efficiency was enhanced for NCE with diesel with the advance in injection timing and the maximum was $93 \%$ found at an injection timing of $34^{\circ}$ BTDC. 


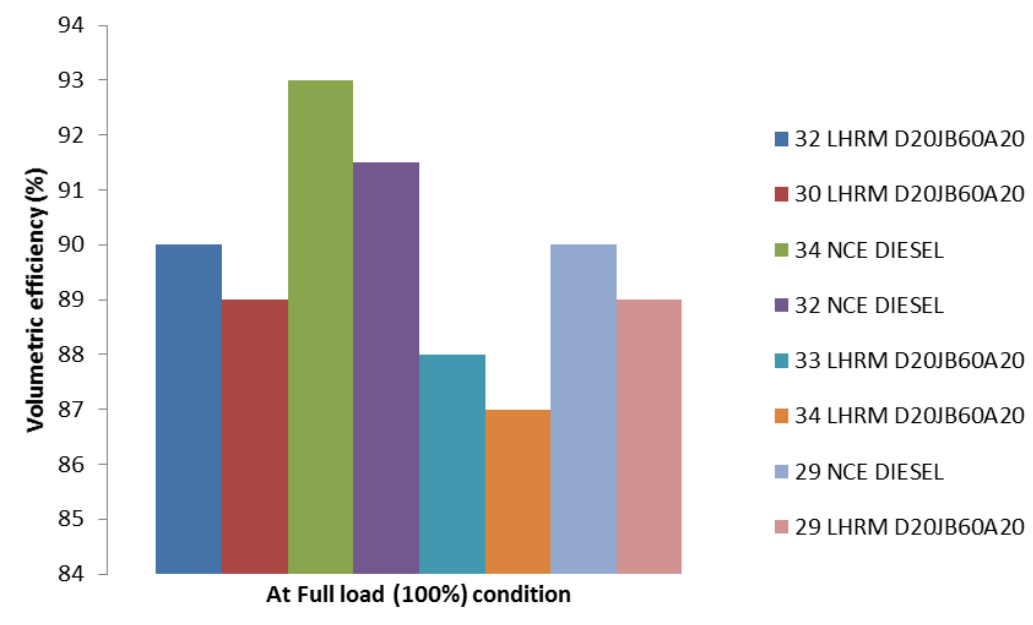

Figure 8. VE of LHRM and NCE for different injection timing at full load.

\section{Emission Characteristics}

Figure 9 shows the smoke levels in the exhaust emissions of LHRM and NCE with blend D20JB60A20 and diesel respectively operated at full load at different IT. Smoke opacity (HSU \%), an easy and low-cost measure of particulate emissions was measured by using the AVL Hartridge smoke meter. It was found that increase in the ratio of biodiesel in blends significantly reduces the smoke density and the optimum reduction of smoke was $44.5 \%$ found with D20JB60A20 at injection timing $32^{\circ}$ BTDC. A marginal higher reduction of smoke was observed for the blend with $80 \%$ biodiesel at $34^{\circ}$ BTDC compared to NCE with diesel. Irrespective of injection timings, the smoke density in emissions were lower for all the blends with LHRM compared to diesel with NCE. This happens due to the rich amount of oxygen content (12 to $13 \%$ ) in the blend, ample hot combustion environment of LHRM and injection timings advancement that ensured superior blend vaporization and complete combustion. The additive diethyl ether in the blend decreased the overall viscosity of the blend and ensured superior combustion characteristics [9]. Consequently, the smoke opacity increased. The details of emission measuring devices were given in Table 5.

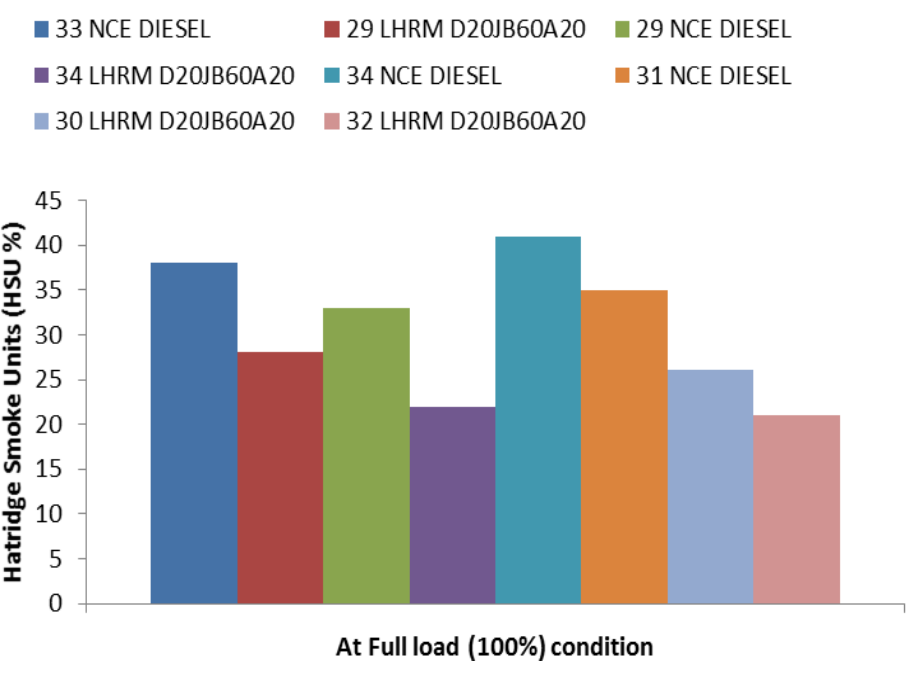

Figure 9. Smoke levels of LHRM and NCE for different injection timing at full load 
Table 5. Specifications of emission measuring devices

\begin{tabular}{|c|c|c|c|c|}
\hline $\begin{array}{c}\text { Device name and } \\
\text { make }\end{array}$ & $\begin{array}{c}\text { Emission measuring } \\
\text { principle }\end{array}$ & $\begin{array}{l}\text { Emission } \\
\text { type }\end{array}$ & $\begin{array}{c}\text { Measuring } \\
\text { range }\end{array}$ & Accuracy \\
\hline $\begin{array}{l}\text { AVL smoke meter, } \\
\text { AVL India Pvt. Ltd. }\end{array}$ & Light extinction & Smoke & $\begin{array}{l}0 \text { to } 100 \% \\
\text { HSU }\end{array}$ & $\pm 0.2 \%$ \\
\hline $\begin{array}{l}\mathrm{NO}_{\mathrm{x}} \text { analyzer, Netel } \\
\text { India Pvt. Ltd. }\end{array}$ & Chemiluminiscen & $\begin{array}{c}\text { Nitrous } \\
\text { Oxide }\left(\mathrm{NO}_{\mathrm{x}}\right)\end{array}$ & $1-5000 \mathrm{ppm}$ & $\pm 10 \mathrm{ppm}$ \\
\hline
\end{tabular}

Figure 10 shows the variation of NOx emissions (ppm) of LHRM and NCE fuelled by test fuels operated at full load for different injection timings. As it was well known that NOx chemistry formation was highly influenced by combustion chamber temperatures and oxygen content availability, EGR assistance at the optimal rate was obligatory to curb the NOx formation. At any specific injection timing, NOx emissions of LHRM coupled with EGR with all the investigated blends were lower compared to NCE fuelled by diesel. The NOx emissions were increased with the increase in the ratio of the biodiesel in blends. The reduction in NOx emissions of $10 \%$ by vol. of EGR assisted LHRM fuelled by optimal blend D20JB60A20 was $10 \%$ at $34^{\circ}$ BTDC, $13.5 \%$ at $30^{\circ}$ BTDC and $14.1 \%$ at $32^{\circ}$ BTDC compared to NCE with diesel at $29^{\circ}$ BTDC (950 ppm).

Hence, the advancement in injection timing increased the NOx formation and this might be due to the availability of residence time for the NOx chemistry to take place. Reduction in the excess amount of oxygen existed with the blend in the combustion chamber was effectively done by the optimum $10 \%$ constant rate of EGR by recirculating the exhaust gases to the inlet manifold of the engine and thus enhancing mixture heat capacity. Much reduction in NOx was expected with the EGR assistance but the contrary conditions like the existence of higher temperature in the combustion chamber of LHRM, high compression ratio 18:1 operation and higher biodiesel ratio in the fuel blend might be influenced. The higher NOx of $1080 \mathrm{ppm}$ was found with NCE fuelled by diesel at an advanced injection timing $34^{\circ}$ BTDC and the lower NOx of $820 \mathrm{ppm}$ was for EGR assisted LHRM at injection timing $32^{\circ}$ BTDC.

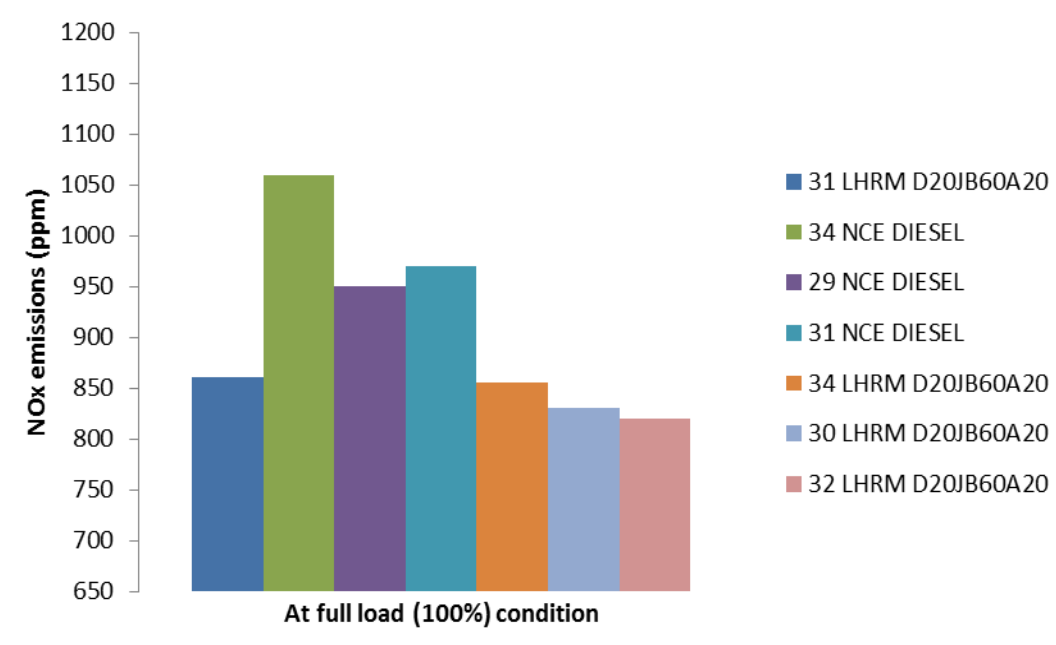

Figure 10. $\mathrm{NO}_{\mathrm{x}}$ of LHRM and NCE for different injection timing at full load 


\section{CONCLUSION}

In this paper, investigation on the performance and emission parameters of a less heat rejection model (LHRM) of diesel engine developed via 8 YSZ ceramic coated cylinder head and liner associated with $10 \%$ optimum rate of EGR and fuelled by different blends of diesel, Jatropha biodiesel and DEE at different loads and injection timings was discussed. Also, to appreciate the parameters, a comparison was carried out with NCE fuelled by neat diesel. From the overall test results, following conclusions were drawn:

a) The EGR coupled YSZ coated less heat rejection model of the diesel engine fuelled by optimum blend with early injection timing at higher load improved the performance and emissions. The rich amount of oxygen content in the blends might play a prime role in this improvement.

b) The optimal blend and injection timing for LHRM were found to be D20JB60A20 and $32^{\circ}$ BTDC.

c) At normal operating conditions (low load \& manufacturer recommended IT), the test model fuelled by the blends showed comparable results to NCE fuelled by diesel.

d) The provision of $10 \%$ vol. of constant EGR rate to LHRM was optimal since it doesn't show any adverse effect on BTE and BSEC besides reducing the NOx emissions greatly.

e) Higher biodiesel ratios (JB $80 \%$ and JB $60 \%$ ) by vol. in the blends were found to be more suitable for LHRM rather than lower biodiesel and higher diesel ratio.

\section{REFERENCES}

[1] https://www.scientificamerican.com/article/earth-will-cross-the-climate-dangerthreshold-by-2036/, article by Michael E. Mann on April 1, 2014. Nature America, Inc. [US]

[2] International Energy Outlook 2016 with projections to 2040 by the U.S. Energy Information Administration (EIA), report number DOE/EIA-0484(2016) I May 2016

[3] Knothe G, Razon LF. Biodiesel fuels. Prog Energy Combust Sci. Elsevier Ltd; 2017;58:36-59.

[4] Mahmudul HM, Hagos FY, Mamat R, Adam AA, Ishak WFW, Alenezi R. Production, characterization and performance of biodiesel as an alternative fuel in diesel engines - A review. Renew Sustain Energy Rev. Elsevier; 2017;72(January):497-509.

[5] Ashraful AM, Masjuki HH, Kalam MA, Rizwanul Fattah IM, Imtenan S, Shahir SA, et al. Production and comparison of fuel properties, engine performance, and emission characteristics of biodiesel from various non-edible vegetable oils: A review. Energy Convers Manag. Elsevier Ltd; 2014;80:202-28.

[6] Pandey VC, Singh K, Singh JS, Kumar A, Singh B, Singh RP. Jatropha curcas: A potential biofuel plant for sustainable environmental development. Renew Sustain Energy Rev. Elsevier Ltd; 2012;16(5):2870-83.

[7] Chauhan BS, Kumar N, Cho HM. A study on the performance and emission of a diesel engine fueled with Jatropha biodiesel oil and its blends. Energy. Elsevier Ltd; 2012;37(1):616-22.

[8] Mofijur M, Masjuki HH, Kalam MA, Atabani AE. Evaluation of biodiesel blending, engine performance and emissions characteristics of Jatropha curcas 
methyl ester: Malaysian perspective. Energy. 2013;55:879-87.

[9] Imtenan S, Masjuki HH, Varman M, Rizwanul Fattah IM, Sajjad H, Arbab MI. Effect of n-butanol and diethyl ether as oxygenated additives on combustionemission-performance characteristics of a multiple cylinder diesel engine fuelled with diesel-jatropha biodiesel blend. Energy Convers Manag. Elsevier Ltd; 2015;94:84-94.

[10] Imtenan S, Masjuki HH, Varman M, Kalam MA, Arbab MI, Sajjad H, et al. Impact of oxygenated additives to palm and jatropha biodiesel blends in the context of performance and emissions characteristics of a light-duty diesel engine. Energy Convers Manag. Elsevier Ltd; 2014;83:149-58.

[11] Tan PQ, Hu ZY, Lou DM, Li ZJ. Exhaust emissions from a light-duty diesel engine with Jatropha biodiesel fuel. Energy. Elsevier Ltd; 2012;39(1):356-62.

[12] Mohamed Shameer P, Ramesh K, Sakthivel R, Purnachandran R. Effects of fuel injection parameters on emission characteristics of diesel engines operating on various biodiesel: A review. Renew Sustain Energy Rev. Elsevier; 2017;67(3):1267-81.

[13] Rostami S, Ghobadian B, Kiani MKD. Effect of the Injection Timing on the Performance of A Diesel Engine using Diesel-biodiesel Blends. Int J Autom Mech Eng. 2014;10:1945-58.

[14] Shahabuddin M, Liaquat AM, Masjuki HH, Kalam MA, Mofijur M. Ignition delay, combustion and emission characteristics of diesel engine fueled with biodiesel. Renew Sustain Energy Rev. Elsevier; 2013;21:623-32.

[15] Vamsi Krishna K, Sastry GRK, Murali Krishna MVS, Deb Barma J. Investigation on performance and emission characteristics of EGR coupled semi adiabatic diesel engine fuelled by DEE blended rubber seed biodiesel. Eng Sci Technol an Int J. 2018;

[16] Kulkarni PS, Sharanappa G, Ramesh MR, Banapurmath NR, Khandal S V. Experimental investigations of a low heat rejection (LHR) engine powered with Mahua oil methyl ester (MOME) with exhaust gas recirculation (EGR). Biofuels. Taylor \& Francis; 2017;7269(July):1-10.

[17] Musthafa MM. Development of performance and emission characteristics on coated diesel engine fuelled by biodiesel with cetane number enhancing additive. Energy. Elsevier B.V.; 2017;134:234-9.

[18] Khalid A, Jaat N, Sapit A, Razali A, Manshoor B, Zaman I, Abdullah AA. Performance and Emissions Characteristics of Crude Jatropha Oil Biodiesel Blends in a Diesel Engine. International Journal of Automotive and Mechanical Engineering 2015;11:2447-57.

[19] Ganapathy T, Gakkhar RP, Murugesan K. Influence of injection timing on performance, combustion and emission characteristics of Jatropha biodiesel engine. Appl Energy. Elsevier Ltd; 2011;88(12):4376-86.

[20] Nayak C, Pattanaik BP, Nayak SK. Effect of preheated Jatropha oil and Jatropha oil methyl ester with producer gas on diesel engine performance. Int $\mathbf{J}$ Automot Mech Eng. 2014;9(1):1709-22.

[21] https://www.americanelements.com/8-yttria-stabilized-zirconia-114168-16-0

[22] Hejwowski T, Weroński A. The effect of thermal barrier coatings on diesel engine performance. Vacuum. 2002;65(3-4):427-32. 